Article

\title{
Iron-Catalyzed Cross-Coupling of Bis-(aryl)manganese Nucleophiles with Alkenyl Halides: Optimization and Mechanistic Investigations
}

\author{
Lidie Rousseau $^{1,2}$, Alexandre Desaintjean ${ }^{3}$, Paul Knochel ${ }^{3}$ and Guillaume Lefèvre ${ }^{1, *}$ \\ 1 Chimie ParisTech, PSL University, CNRS, Institute of Chemistry for Life and Health Sciences (i-CLeHS \\ FRE2027), CSB2D, 75005 Paris, France; lidie.rousseau@cea.fr \\ 2 NIMBE, CEA, CNRS, Univ. Paris-Saclay, 91191 Gif-sur-Yvette, France \\ 3 Department of Chemistry, Ludwig-Maximilians-Universitat München, Butenandstr. 5-13, Haus F, \\ 81377 Munich, Germany; Alexandre.Desaintjean@cup.uni-muenchen.de (A.D.); \\ Paul.Knochel@cup.uni-muenchen.de (P.K.) \\ * Correspondence: guillaume.lefevre@chimieparistech.psl.eu; Tel.: +33-1-85-78-41-70
}

Received: 15 January 2020; Accepted: 6 February 2020; Published: 7 February 2020

\begin{abstract}
Various substituted bis-(aryl)manganese species were prepared from aryl bromides by one-pot insertion of magnesium turnings in the presence of $\mathrm{LiCl}$ and in situ trans-metalation with $\mathrm{MnCl}_{2}$ in THF at $-5^{\circ} \mathrm{C}$ within $2 \mathrm{~h}$. These bis-(aryl)manganese reagents undergo smooth iron-catalyzed cross-couplings using $10 \mathrm{~mol} \% \mathrm{Fe}(\mathrm{acac})_{3}$ with various functionalized alkenyl iodides and bromides in $1 \mathrm{~h}$ at $25^{\circ} \mathrm{C}$. The aryl-alkenyl cross-coupling reaction mechanism was thoroughly investigated through paramagnetic ${ }^{1} \mathrm{H}-\mathrm{NMR}$, which identified the key role of tris-coordinated ate-iron(II) species in the catalytic process.
\end{abstract}

Keywords: iron catalysis; cross-coupling; bis-(aryl)manganese; alkenyl halides; ate iron(II) complex

\section{Introduction}

Transition-metal catalyzed cross-couplings are widely used in the development and production of pharmaceutical compounds [1]. The most versatile of them are palladium-catalyzed and nickel-catalyzed cross-couplings [2-5] as they tolerate a great variety of functionalities on both coupling partners. Yet, these metals have drawbacks such as toxicity $[6,7]$ and high prices in the case of palladium [8]. That is one of the reasons why copper [9], iron [10-13], or cobalt [14] have been developed as alternative metal-catalysts.

Organomanganese species pioneered by Cahiez [15] often considerably reduce the amount of side reactions such as homo-coupling $[16,17]$ and have proven to be excellent nucleophiles in various types of reactions [18-24] including cross-couplings [25,26]. Organomanganese species then constitute an interesting alternative to usual cross-coupling partners such as organomagnesium [27], organozinc [28], and organo-boronic esters, which may have genotoxic properties $[29,30]$.

Recently, we have developed a two-step preparation of functionalized bis-(aryl)manganese reagents by oxidative insertion of magnesium into the $\mathrm{C}-\mathrm{Br}$ bond of aryl bromides, which is followed by a trans-metalation with $\mathrm{MnCl}_{2} \cdot 2 \mathrm{LiCl}$ [31]. Herein, we wish to report an effective one-pot preparation of those functionalized bis-(aryl)manganese reagents $\left(\mathrm{Ar}_{2} \mathrm{Mn} \bullet 2 \mathrm{MgX} \mathrm{X}_{2} \bullet 4 \mathrm{LiCl}\right.$, denoted as $\mathrm{Ar}_{2} \mathrm{Mn}(1)$, Scheme 1) starting from aryl bromides, which are followed by an iron-catalyzed cross-coupling of 1 with alkenyl iodides and bromides, and provide a range of polyfunctionalized alkenes (4, Scheme 1$)$. These bis-(aryl)manganese reagents are generally stable at RT $\left(25^{\circ} \mathrm{C}\right)$ for several hours, which makes them suitable reagents for mild cross-coupling reactions [32]. 


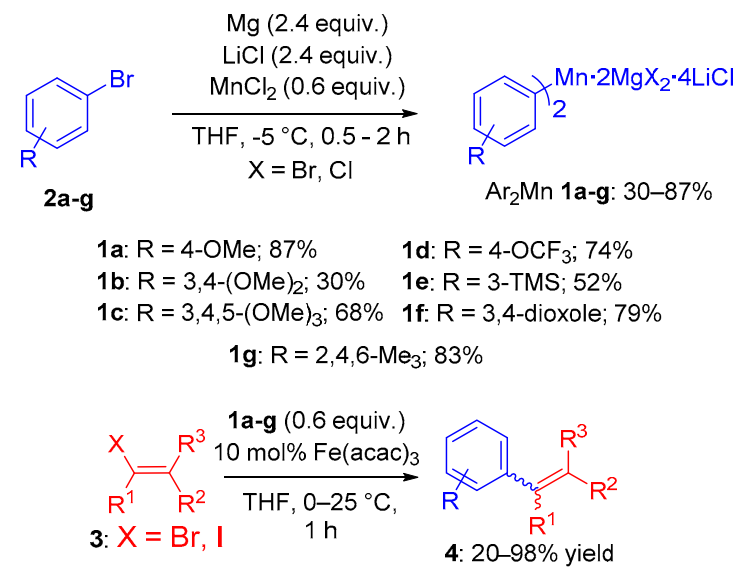

Scheme 1. One-pot preparation of bis-(aryl)manganese reagents by in situ trans-metalation followed by iron-catalyzed cross-couplings with alkenyl iodides and bromides.

\section{Results}

In preliminary experiments, the bis-(aryl)manganese reagent 1a was conveniently prepared by treating 4-bromoanisole (2a, 1.0 equiv.) in THF at $-5^{\circ} \mathrm{C}$ with magnesium turnings and $\mathrm{LiCl}$ (2.4 equiv.) in the presence of $\mathrm{MnCl}_{2}$ (0.6 equiv.) within $1 \mathrm{~h}$. Titration [31] with iodine led to a yield for $1 \mathrm{a}$ of $87 \%$. Cross-coupling methodologies involving those bis-(aryl)manganese species were then investigated (see Supporting Information file for details).

In the absence of any iron catalyst, the cross-coupling of $\mathbf{1 a}$ with $(Z)$-ethyl 3-iodoacrylate $\left(\mathbf{3 a} ; 25^{\circ} \mathrm{C}\right.$, $1 \mathrm{~h}$ ) produced a $Z / E=50: 50$ mixture of the desired cross-coupling product $4 \mathbf{a}$ in $60 \%$ yield (Table 1 , entry 1). Although the cross-coupling performed with $\mathrm{FeBr}_{2}$ gave a moderate yield of $42 \%$, the use of $\mathrm{FeCl}_{3}, \mathrm{FeBr}_{3}$, or $\mathrm{FeCl}_{2}$ afforded the $E$ isomer of $4 \mathrm{a}$ in $54-64 \%$ yield (entries $\left.2-5\right)$. Using $\mathrm{Fe}(\mathrm{acac})_{2}$ proved to be more effective since the yield increased to $67 \%$ (entry 6). Our best result was obtained with $\mathrm{Fe}(\mathrm{acac})_{3}$ ( $>99 \%$ purity) as a catalyst, producing the $E$ isomer of 4 a in a $79 \%$ yield (entry 7$)$.

Table 1. Catalyst screening of the reaction between the bis-(aryl)manganese reagent 1a and (Z)-ethyl 3-iodoacrylate (3a).

\begin{tabular}{ccc} 
1a: 0.6 equiv. & $\begin{array}{c}\text { Fe-catalyst }(10 \mathrm{~mol} \%) \\
\mathrm{THF}, 0^{\circ} \mathrm{C} \text { to } 25^{\circ} \mathrm{C}, 1 \mathrm{~h}\end{array}$ \\
\hline Entry & Catalyst $(\mathbf{1 0} \mathbf{~ m o l \% )}$ & Yield (\%) ${ }^{\mathbf{a}}$ \\
\hline 1 & none & $60^{\mathrm{b}}$ \\
2 & $\mathrm{FeBr}_{2}$ & 42 \\
3 & $\mathrm{FeCl}_{3}$ & 54 \\
4 & $\mathrm{FeBr}_{3}$ & 57 \\
5 & $\mathrm{FeCl}_{2}$ & 64 \\
6 & $\mathrm{Fe}(\mathrm{acac})_{2}$ & 67 \\
7 & $\mathrm{Fe}(\mathrm{acac})_{3}(>99 \%$ purity $)$ & 79 \\
\hline
\end{tabular}

a Yield of analytically pure product. ${ }^{\mathrm{b}} \mathrm{A}$ Z/E $=50: 50$ mixture of $4 \mathbf{a}$ was obtained.

Furthermore, the cross-coupling of 1a with (2-bromovinyl)trimethylsilane $(3 \mathbf{b} ; Z / E=10: 90)$ gave the olefin $4 \mathbf{b}$ in $98 \%$ yield with complete $E$-selectivity $(Z / E=1: 99)$ whereas the yield without iron salt was $24 \%(Z / E=20: 80$, Table 2, entry 1$)$. When the electron-rich bis-(3,4-dimethoxyphenyl)manganese (1b) was mixed with $3 \mathbf{a}$, the $E$-acrylate $4 \mathrm{c}$ was generated in $69 \%$ yield and a $Z / E=69: 31$ mixture of products was obtained in $58 \%$ yield without an iron catalyst (entry 2). The tri-substituted bis-(3,4,5-trimethoxyphenyl)manganese (1c) underwent smooth cross-coupling with $\mathbf{3 b}$ to afford the E-alkene $4 \mathbf{d}$ in $80 \%$ ( $8 \%$ were obtained without a catalyst, entry 3$)$. Additionally, 1c reacted with 
3a and 2-bromostyrene (3c; $Z / E=18: 82)$ to give the acrylate $4 \mathbf{e}$ and $4 \mathbf{f}(Z / E=1: 99)$ in $57 \%$ and $82 \%$ yield whereas $66 \%(Z / E=72: 28)$ and $80 \%(Z / E=53: 47)$ were, respectively, obtained without a catalyst (entries 4-5). In the last experiment, 1c reacted with (E)-1-iodooctene (3d) to provide the alkene $\mathbf{4 g}$ in $87 \%$ yield $(Z / E=9: 91)$ when $77 \%$ yield $(Z / E=4: 96)$ was obtained without a catalyst (entry 6$)$. Furthermore, bis-(4-(trifluoromethoxy)phenyl)manganese (1d) reacted with 3a to provide the acrylate 4h $(Z / E=1: 99)$ in $77 \%$ yield (entry 7$)$. The reaction without $\mathrm{Fe}(\mathrm{acac})_{3}$ gave a similar yield but a mix of the two isomers $(74 \%, Z / E=81: 19$, entry 7$)$. The silicon-containing bis-(aryl)manganese reagent 1e could also react with $3 \mathbf{a}$, which produces $4 \mathbf{i}(Z / E=1: 99)$ in $64 \%$ yield $(51 \%, Z / E=57: 43$ were obtained without $\mathrm{Fe}(\text { acac })_{3}$, entry 8$)$. Some good yields could be achieved in the absence of the iron catalyst (entries 2,4-8), which could be attributed to the catalytic activity of the manganese(II) itself. For example, manganese salts proved to efficiently catalyze several couplings of organomagnesium reagents with alkenyl electrophiles in the past [32]. The bis-benzo[d][1,3]dioxol-5-ylmanganese (1f) also reacted with $\mathbf{3 a}$ and $\mathbf{3 b}$ to yield the E-alkenes $\mathbf{4 j}$ and $4 \mathbf{k}$ in $78-84 \%$ yield (entries $9-10)$. The bulkier bis-mesitylmanganese $\mathbf{1 g}$ reacted with $\mathbf{3 b}$ to afford 41 with a small $20 \%$ yield (91\% after $18 \mathrm{~h}$, entry 11$)$. This method also proved to tolerate nitriles, since 4-(2-bromovinyl)benzonitrile $3 \mathbf{e}(Z / E=98: 2)$ could be used as a coupling partner with 1d and 1e in good yields (entries 12-13). Moreover, the coupling generally proceeds with an excellent $E$-selectivity when iodoalkenes are used. Total isomerization is observed for Z-starting iodoalkenes (entries 2, 4, 7, 8, 10). A similar tendency is observed for bromoalkenes, with the exception of 4-(2-bromovinyl)benzonitrile $3 \mathbf{e}(Z / E=98: 2)$, which, intriguingly, did not lead to isomerization of the starting $Z$ bond when coupled with nucleophile 1d, entry 12 , or to a slight isomerization when coupled with 1e, entry 13. In all cases, efficient transference of both aryl groups from the starting bis-(aryl)manganese species has been observed.

Table 2. Iron-catalyzed couplings of bis-(aryl)manganese (1a-g) ${ }^{a}$ with alkenyl electrophiles (3a-e).

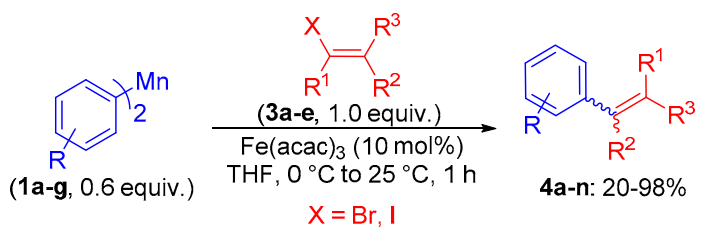

$\mathrm{R}=3$-TMS; 4-OMe; 4-OCF 3 ; 3,4-(OMe $)_{2} ; 3,4,5-(\mathrm{OMe})_{3}$; 3,4-dioxole; 2,4,6- $\mathrm{Me}_{3}$

\begin{tabular}{|c|c|c|c|c|c|c|c|}
\hline Entry & $\mathrm{Ar}_{2} \mathrm{Mn}$ & Electrophile & Yield (\%) ${ }^{b}$ & Entry & $\mathrm{Ar}_{2} \mathrm{Mn}$ & Electrophile & Yield (\%) ${ }^{b}$ \\
\hline 1 & 1a & $\begin{array}{c}\mathrm{Br} / \mathrm{m}_{\mathrm{TMS}} \\
\text { 3b: } Z / E=10: 90\end{array}$ & $\begin{array}{l}\text { 4b: } 98, Z / E=1: 99 \\
(24, Z / E=20: 80)^{c}\end{array}$ & 8 & 1e & $3 a$ & $\begin{array}{c}\text { TMS } \\
4 \mathbf{i}: 64, Z / E=1: 99 \\
(51, Z / E=57: 43)^{c}\end{array}$ \\
\hline 2 & $1 b$ & $3 a$ & $\begin{array}{l}\text { 4c: } 69, \mathrm{Z} / E=1: 99 \\
(58, \mathrm{Z} / E=69: 31)^{\mathrm{c}}\end{array}$ & 9 & 1f & $\begin{array}{c}\mathrm{Br}_{\backslash} / \mathrm{m}_{\mathrm{TMS}} \\
3 \mathbf{b}: Z / E=10: 90\end{array}$ & $\begin{array}{c}4 \mathbf{j}: 78 \\
Z / E=1: 99 \\
(39, Z / E=20: 80)^{\mathrm{c}}\end{array}$ \\
\hline 3 & 1c & $\begin{array}{c}\mathrm{Br} / \mathrm{m} \text { тMS } \\
3 \mathbf{b}: \mathrm{Z} / E=10: 90\end{array}$ & $\begin{array}{c}\text { OMe } \\
\text { 4d: } 80, Z / E=1: 99 \\
(8, Z / E=1: 99)^{c}\end{array}$ & 10 & If & $3 a$ & $\begin{array}{l}\mathbf{C O}_{2} \mathrm{Et} \\
(48, \mathrm{Z} / \mathrm{E}=99: 1)^{\mathrm{c}}\end{array}$ \\
\hline 4 & 1c & $3 a$ & $\begin{array}{l}\text { 4e: } 57, \mathrm{Z} / E=1: 99 \\
(66, \mathrm{Z} / E=72: 28)^{\mathrm{c}}\end{array}$ & 11 & $1 \mathrm{~g}$ & $\begin{array}{c}\mathrm{Br} / m_{\text {TMS }} \\
\text { 3b: } Z / E=10: 90\end{array}$ & 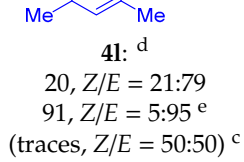 \\
\hline
\end{tabular}


Table 2. Cont.

\begin{tabular}{|c|c|c|c|c|c|c|c|}
\hline Entry & $\mathrm{Ar}_{2} \mathrm{Mn}$ & Electrophile & Yield $(\%)^{b}$ & Entry & $\mathrm{Ar}_{2} \mathrm{Mn}$ & Electrophile & Yield $(\%)^{b}$ \\
\hline 5 & 1c & 3c: $Z / E=18: 82$ & $\begin{array}{c}\text { Of: } 82, Z / E=1: 99 \\
(80, Z / E=53: 47)^{c}\end{array}$ & 12 & $1 d$ & 3e: $Z / E=98: 2$ & $\begin{array}{l}\text { 4m: } 74, Z / E=98: 2 \\
(19, Z / E=73: 27)^{c}\end{array}$ \\
\hline 6 & 1c & $3 d$ & $\begin{array}{c}\text { OMe } \\
\text { 4g: } 87, Z / E=9: 91 \\
(77, Z / E=4: 96)^{c}\end{array}$ & 13 & $1 e$ & 3e: $Z / E=98: 2$ & $\begin{array}{c}Y_{C N} \\
\text { 4n: } 66, Z / E=70: 30 \\
(41, Z / E=72: 28)^{\mathrm{c}}\end{array}$ \\
\hline 7 & 1d & $3 a$ & $\begin{array}{l}\text { 4h: } 77, Z / E=1: 99 \\
(74, Z / E=81: 19)^{c}\end{array}$ & & & & \\
\hline
\end{tabular}

${ }^{a}$ For clarity reasons, the magnesium salt has been omitted. ${ }^{b}$ Yield of analytically pure product. ${ }^{\mathrm{c}}$ In parentheses, yield and Z/E ratio obtained without catalysis. ${ }^{\mathrm{d}}$ Yields determined by GC and ${ }^{1} \mathrm{H}-\mathrm{NMR}$. ${ }^{\mathrm{e}}$ After $18 \mathrm{~h}$.

\section{Discussion}

In order to rationalize some of the mechanistic features of the transformations reported in the first section, we focused our efforts on the coupling system involving various bis-(aryl)manganese nucleophiles (bis-mesitylmanganese and bis-phenylmanganese) with (2-bromovinyl)-trimethylsilane (3b). This choice has been motivated by the low cross-coupling yields obtained with this electrophile in the absence of the iron catalyst, which ascertains the requirement of an Fe-based catalysis for this coupling (see Table 2, entries 1, 3, 9 and 11).

The bis-(mesityl)manganese reagent was prepared by adding $\operatorname{MesMgBr}$ (2.0 equiv.) into a solution of $\mathrm{MnCl}_{2} \bullet \mathrm{LiCl}$ (1.0 equiv.) in THF at $-5{ }^{\circ} \mathrm{C}$ within $1 \mathrm{~h} .{ }^{1} \mathrm{H}-\mathrm{NMR}$ showed no free MesMgBr left. The spectra presented high signal-to-noise ratios and broad signals, due to the high paramagnetism of manganese(II) species, which could not be attributed to a specific molecule (Figure 1a) [33]. High-spin organomanganese compounds are often reported to be NMR silent [34] or without NMR characterization at all [35-37]. Yet, after addition of a catalytic load of $\mathrm{FeCl}_{2}$ ( 0.10 equiv.) to the $\mathrm{Mes}_{2} \mathrm{Mn}$ solution, the ate complex $\left[\mathrm{Mes}_{3} \mathrm{Fe}^{\mathrm{II}}\right]^{-}$was detected by ${ }^{1} \mathrm{H}-\mathrm{NMR}$ from the three signals at $127 \mathrm{ppm}(\mathrm{s}$, $6 \mathrm{H}$, meta- $\mathrm{H}$ of the Mes group), $110 \mathrm{ppm}\left(\mathrm{s}, 9 \mathrm{H}\right.$, para- $\mathrm{CH}_{3}$ ), and $26 \mathrm{ppm}\left(\mathrm{bs}, 18 \mathrm{H}\right.$, ortho- $\left.\mathrm{CH}_{3}\right)$, as shown in Figure $1 b$. These signals attest to a strong paramagnetism, due to the high-spin $(S=2)$ configuration of this complex [38]. This proves a fast trans-metalation of the aryl groups from the manganese toward the iron(II) center. A similar result was obtained while adding an excess of the $\mathrm{Mes}_{2} \mathrm{Mn}$ solution onto $\mathrm{Fe}(\mathrm{acac})_{3}$ (0.10 equiv.) as an iron(III) precursor. [ $\left.\mathrm{Mes}_{3} \mathrm{Fe}^{\mathrm{II}}\right]^{-}$was detected by ${ }^{1} \mathrm{H}-\mathrm{NMR}$, showing that, when an iron(III) precursor is used, a first 1-electron reduction of the latter by the nucleophile can take place, affording an iron(II) species. This is in agreement with recent reports by Neidig [39] and by some of us [40] regarding the reduction of iron(III) salts by Grignard reagents as $\mathrm{MeMgBr}$ and $\mathrm{PhMgBr}$. Accordingly, all the mechanistic studies discussed thereafter were performed using an iron(II) precursor.

Upon addition of the electrophile $\mathbf{3} \mathbf{b}$ ((2-bromovinyl)trimethylsilane) to a mixture of $\mathrm{FeCl}_{2}$ and $\mathrm{Mes}_{2} \mathrm{Mn}$ at $25^{\circ} \mathrm{C}$, the signals corresponding to $\left[\mathrm{Mes}_{3} \mathrm{Fe}^{\mathrm{II}}\right]^{-}$were observed to slowly decrease, affording $\left[\mathrm{Mes}_{2} \mathrm{BrFe}^{\mathrm{II}}\right]^{-}$, characterized by new signals at $128 \mathrm{ppm}(\mathrm{s}, 4 \mathrm{H}$, meta-H of the Mes group), $104 \mathrm{ppm}$ $\left(\mathrm{s}, 6 \mathrm{H}\right.$, para- $\mathrm{CH}_{3}$ ), and $29 \mathrm{ppm}$ (bs, $12 \mathrm{H}$, ortho- $\mathrm{CH}_{3}$ ) (see Figure 1c) (this tricoordinate ate species also presents a high-spin $S=2$ configuration) [38]. The same reaction was run at $25^{\circ} \mathrm{C}$ for $1 \mathrm{~h}$, then quenched, and analyzed by GC-MS, which proved formation of the desired cross-coupling product with a low conversion (ca. 20\%). This is in fair agreement with the result given in Table 2, entry 11 (due to the high 
paramagnetism of the NMR-analyzed solution and due to the presence of non-deuterated solvents (THF solutions of organometallics), NMR monitoring of the coupling product formation could not be efficiently performed).

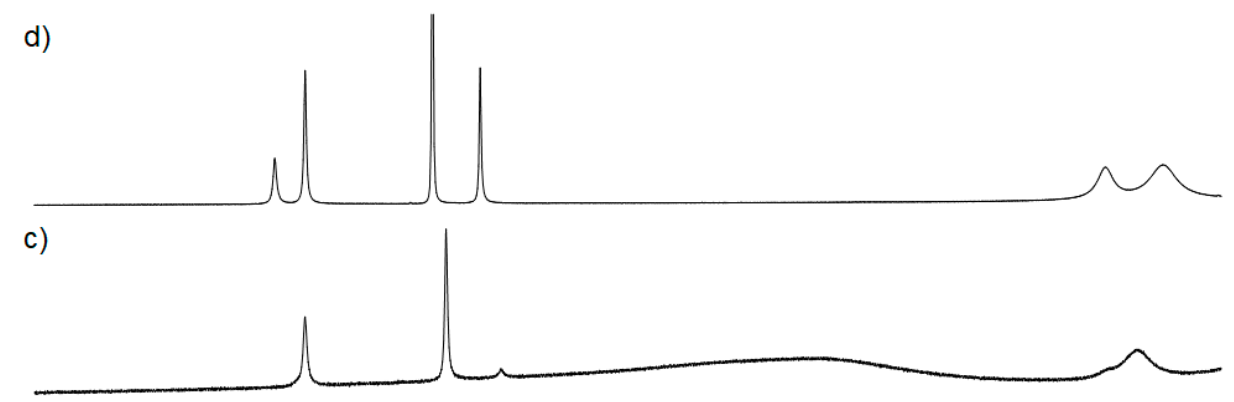

b)

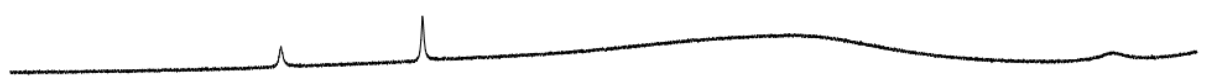

a)

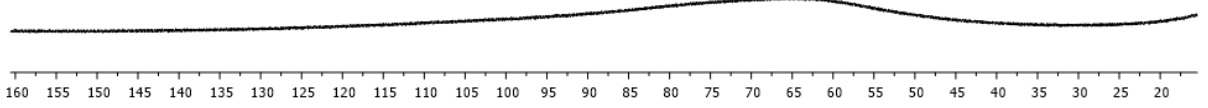

Figure 1. ${ }^{1} \mathrm{H}-\mathrm{NMR}$ spectra (recorded at $25^{\circ} \mathrm{C}$ in $d_{8}$-THF) of a $0.08 \mathrm{M}$ solution of (a) $\mathrm{Mes}_{2} \mathrm{Mn}$, (b) $\mathrm{Mes}_{2} \mathrm{Mn}$ +0.10 equiv. $\mathrm{FeCl}_{2}$, (c) $\mathrm{Mes}_{2} \mathrm{Mn}+0.10$ equiv. $\mathrm{FeCl}_{2}+1.0$ equiv. 3 b, (d) $\mathrm{FeCl}_{2}+3.0$ equiv. $\mathrm{MesMgBr}+$ 10 equiv. $3 \mathbf{b}$.

The same observations were made while performing the coupling of $\mathbf{3} \mathbf{b}$ with $\mathrm{MesMgBr}$ as a sole nucleophilic partner in a Kumada-type reaction using $\mathrm{FeCl}_{2}$, as $\left[\mathrm{Mes}_{3} \mathrm{Fe}^{\mathrm{II}}\right]^{-}$and $\left[\mathrm{Mes}_{2} \mathrm{BrFe}^{\mathrm{II}}\right]^{-}$ were also detected under these cross-coupling conditions (Figure $1 \mathrm{~d}$, in the absence of manganese, the signals of [ $\left.\mathrm{Mes}_{2} \mathrm{BrFe}^{\mathrm{II}}\right]^{-}$shifted to 131, 106, and $\left.30 \mathrm{ppm}\right)$. These series of experiments, therefore, confirm that both $\left[\mathrm{Ar}_{3} \mathrm{Fe}^{\mathrm{II}}\right]^{-}$and $\left[\mathrm{Ar}_{2} \mathrm{BrFe}^{\mathrm{II}}\right]^{-}$ate complexes are part of a coupling catalytic cycle and $\left[\mathrm{Ar}_{3} \mathrm{Fe}^{\mathrm{II}}\right]^{-}$can be involved in the activation step of the electrophile. The following catalytic cycle (Scheme 2) can be suggested, which echoes recent reports by Neidig on the Fe-catalyzed alkyl-alkenyl coupling reactions [39], and by ourselves on the benzyl-alkenyl coupling [26].

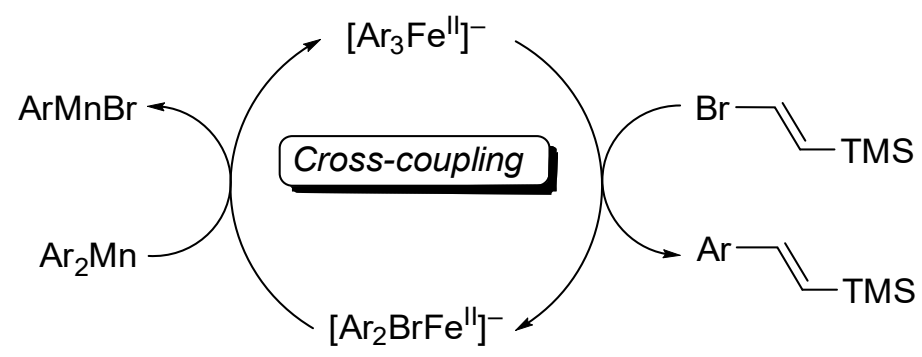

Scheme 2. Proposed catalytic cycle for the aryl-alkenyl cross-coupling between $\mathrm{Ar}_{2} \mathrm{Mn}$ and an alkenyl bromide under Fe-catalytic conditions.

Thanks to the steric hindrance in the ortho positions, the ate $\left[\mathrm{Mes}_{3} \mathrm{Fe}^{\mathrm{II}}\right]^{-}$species remains stable for hours at $25^{\circ} \mathrm{C}[38,41]$. Thus, the use of a mesityl nucleophile in the mechanistic experiments discussed earlier prevents any degradation of the $\mathrm{Fe}^{\mathrm{II}}$ catalyst toward lower oxidation states. In order to delineate the influence of the formation of lower oxidation states on the system, additional investigations were, therefore, carried out using $\mathrm{PhMgBr}$ as a less hindered nucleophile [42]. 
First, $\left[\mathrm{Ph}_{3} \mathrm{Fe}^{\mathrm{II}}\right]^{-}$was generated at $-20{ }^{\circ} \mathrm{C}$ by stoichiometric trans-metalation between $\mathrm{FeCl}_{2}$ and 3.0 equiv. of $\mathrm{PhMgBr}$, and characterized by its ${ }^{1} \mathrm{H}-\mathrm{NMR}$ signals at 116 and $-41 \mathrm{ppm}$. As we recently reported, $\left[\mathrm{Ph}_{3} \mathrm{Fe}^{\mathrm{II}}\right]^{-}$is stable for more than $1 \mathrm{~h}$ at this temperature [40,41]. Its fate upon addition of an excess of the electrophile $3 \mathbf{b}$ (10 equiv.) was then monitored by paramagnetic ${ }^{1} \mathrm{H}-\mathrm{NMR}$. $\left[\mathrm{Ph}_{3} \mathrm{Fe}^{\mathrm{II}}\right]^{-}$ reacted rapidly, as attested by the decrease of its resonances (ca. $75 \%$ of the starting $\left[\mathrm{Ph}_{3} \mathrm{Fe}^{\mathrm{II}}\right]^{-}$reacted after $10 \mathrm{~min}$ ). The reaction was quenched after $1 \mathrm{~h}$, and the GC-MS confirmed formation of the cross-coupling product, which confirms that $\left[\mathrm{Ph}_{3} \mathrm{Fe}^{\mathrm{II}}\right]^{-}$was able to react with $3 \mathbf{b}$ in a cross-coupling process, akin to $\left[\mathrm{Mes}_{3} \mathrm{Fe}^{\mathrm{II}}\right]^{-}$. Moreover, several transient resonances in the $-15 /-5 \mathrm{ppm}$ area could also be detected in the course of the reaction (see Figure 2). These elusive resonances quickly disappeared, and were not detected after $30 \mathrm{~min}$ at $-20{ }^{\circ} \mathrm{C}$. These signals echo the formation of $\left(\eta^{2}-a l k e n e\right){ }_{n}-F^{0}$ intermediates, as recently reported by Deng, which exhibit similar resonances [43]. This suggests that $\mathrm{Fe}^{0}$ species are formed in situ by 2-electron reductive elimination from $\left[\mathrm{Ph}_{3} \mathrm{Fe}^{\mathrm{II}}\right]^{-}$, which is in agreement with a recent report by some of us demonstrating that the evolution of $\left[\mathrm{Ph}_{3} \mathrm{Fe}^{\mathrm{II}}\right]^{-}$led to the formation of a distribution of $\mathrm{Fe}^{0}$ and $\mathrm{Fe}^{\mathrm{I}}$ oxidation states (identified as $\left(\eta^{4} \text {-arene }\right)_{2} \mathrm{Fe}^{0}$ and $\left[\left(\eta^{6} \text {-arene }\right) \mathrm{Fe}^{\mathrm{I}}(\mathrm{Ph})_{2}\right]^{-}$, "arene" being an aromatic ligand present in the bulk medium (e.g., $\mathrm{C}_{6} \mathrm{H}_{6}$ or $\mathrm{C}_{6} \mathrm{H}_{5}-\mathrm{C}_{6} \mathrm{H}_{5}$ coming from the oxidation of $\mathrm{PhMgBr}$ ). $\mathrm{Fe}^{0}$ being preponderantly formed $\left.[40,41]\right)$. Those $\mathrm{Fe}^{0}$ intermediates would then be trapped by alkene ligands present in the bulk medium, which leads to the observed resonances.

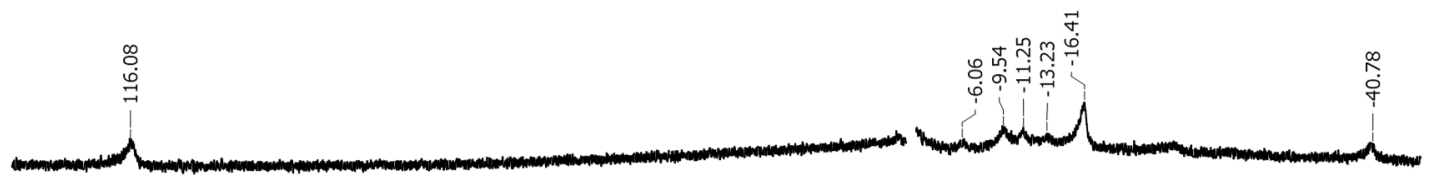

$\begin{array}{lllllllllllllllllllllllllllllll}125 & 120 & 115 & 110 & 105 & 100 & 95 & 90 & 85 & 80 & 75 & 70 & 65 & 60 & 55 & -5 & -10 & -15 & -20 & -25 & -30 & -35 & -40 & \end{array}$

Figure 2. ${ }^{1} \mathrm{H}-\mathrm{NMR}$ spectrum (recorded at $-20{ }^{\circ} \mathrm{C}$ in $d_{8}$-THF) of a $0.08 \mathrm{M}$ solution of $\left[\mathrm{Ph}_{3} \mathrm{Fe}^{\mathrm{II}}\right]^{-}$followed by addition of $\mathbf{3 b}$ (10 equiv.). Spectrum recorded $20 \mathrm{~min}$ after addition of $\mathbf{3 b}$.

Then, the reactivity of the low valent $\mathrm{Fe}^{0}$ and $\mathrm{Fe}^{\mathrm{I}}$ oxidation states in the reaction medium was investigated. Following one of our recent procedures, reduction of $\mathrm{Fe}^{\mathrm{II}}$ into a distribution of $\mathrm{Fe}^{0}$ and $\mathrm{Fe}^{\mathrm{I}}$ species was performed, by fast trans-metalation between $\mathrm{FeCl}_{2}$ and $\mathrm{PhMgBr}(2.0$ equiv.) at room temperature [40,41]. After $10 \mathrm{~min}, 1.0$ equiv. of MesMgBr was added. The ${ }^{1} \mathrm{H}-\mathrm{NMR}$ spectrum showed no signal in the 100-150 ppm area, which attests to the absence of any Mes-Fe ${ }^{\mathrm{II}}$ species, which shows that all the starting $\mathrm{Fe}^{\mathrm{II}}$ was reduced by $\mathrm{PhMgBr}$ (Figure 3a).

b)

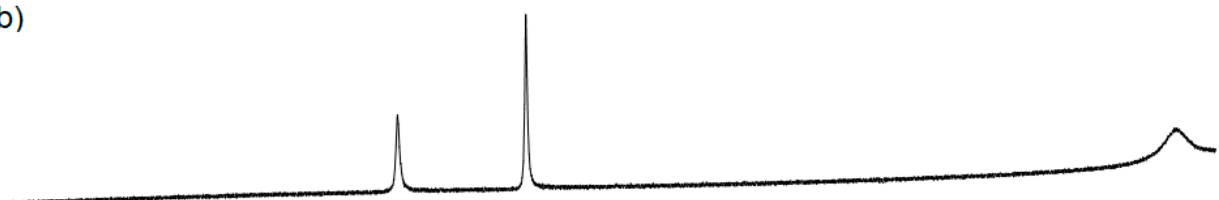

a)

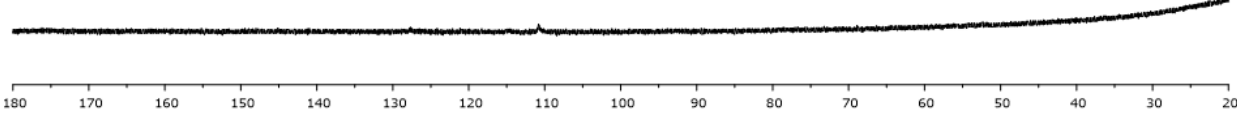

Figure 3. ${ }^{1} \mathrm{H}-\mathrm{NMR}$ spectra (recorded at $25^{\circ} \mathrm{C}$ in $d_{8}$-THF) of a $0.08 \mathrm{M}$ solution of (a) $\mathrm{FeCl}_{2}+2.0$ equiv. $\mathrm{PhMgBr},+1.0$ equiv. MesMgBr after $10 \mathrm{~min}$ agitation at RT. (b) Same tube, +3.0 equiv. $\mathbf{3 b}$, after $30 \mathrm{~min}$.

The addition of 3.0 equiv. of the electrophile $3 \mathbf{b}$ to the in situ generated solution of $\mathrm{Fe}^{0}$ and $\mathrm{Fe}^{\mathrm{I}}$ species led to a color change of the sample, which turned from dark brown to yellow. The ${ }^{1} \mathrm{H}-\mathrm{NMR}$ spectrum showed that, after $30 \mathrm{~min}$, ca. $20 \%$ of the iron contained in the solution was converted into $\left[\mathrm{Mes}_{3} \mathrm{Fe}^{\mathrm{II}}\right]^{-}$(Figure $3 \mathbf{b}$ ). The presence of $\mathbf{3 b}$, therefore, allows a re-oxidation of the reduced $\mathrm{Fe}^{0}$ and/or $\mathrm{Fe}^{\mathrm{I}}$ species to the $\mathrm{Fe}^{\mathrm{II}}$ oxidation state, the latter being trapped by trans-metalation with 
$\mathrm{MesMgBr}$ to afford $\left[\mathrm{Mes}_{3} \mathrm{Fe}^{\mathrm{II}}\right]^{-}$. The re-oxidation of low iron oxidation states by $\mathbf{3} \mathbf{b}$ to the $\mathrm{Fe}^{\mathrm{II}}$ stage was also confirmed by the observation of bis(trimethylsilyl)butadienes TMS- $\mathrm{CH}=\mathrm{CH}-\mathrm{CH}=\mathrm{CH}-\mathrm{TMS}$ (TMS- $(\mathrm{CH})_{4}$-TMS, E/E; Z/E; Z/Z) in GC-MS, after catalytic reactions involving $10 \mathrm{~mol} \% \mathrm{of} \mathrm{FeCl}_{2}$, $\mathrm{PhMgBr}$, and $3 \mathrm{~b}$ as coupling partners. Formation of TMS- $(\mathrm{CH})_{4}$-TMS undoubtedly comes from the sacrificial monoelectronic reduction of the electrophile that permits re-oxidation of the low $\mathrm{Fe}^{0}$ and/or $\mathrm{Fe}^{\mathrm{I}}$ oxidation states. TMS- $(\mathrm{CH})_{4}$-TMS, moreover, also appears as a suitable ligand for $\mathrm{Fe}^{0}$ oxidation state, and a ( $\left.\eta^{4}-\mathrm{TMS}-(\mathrm{CH})_{4}-\mathrm{TMS}\right) \mathrm{Fe}^{0}$ complex might, thus, contribute to the group of high field resonances in the in the $-15 /-5 \mathrm{ppm}$ area (Figure 2). Quantity of detected TMS- $(\mathrm{CH})_{4}$-TMS represents ca. $10 \%$ of the quantity of a detected coupling product, which shows that this off-cycle sacrificial reduction pathway is not preponderant. By comparison, no traces of TMS- $(\mathrm{CH})_{4}$-TMS were detected when using mesityl nucleophiles (conditions of Figure 1), attesting that no sacrificial 1-electron reduction of $3 \mathbf{b}$ by oxidation states lower than $\mathrm{Fe}^{\mathrm{II}}$ formed in situ occurred.

Scheme 3 presents a summary of the competitive reactions that were observed in this work during the Fe-catalyzed coupling of $\mathrm{Ph}_{2} \mathrm{Mn}$ with (2-bromovinyl)-trimethylsilane (3b), taking into account the possibility of an off-cycle process involving in situ formed low iron oxidation states.

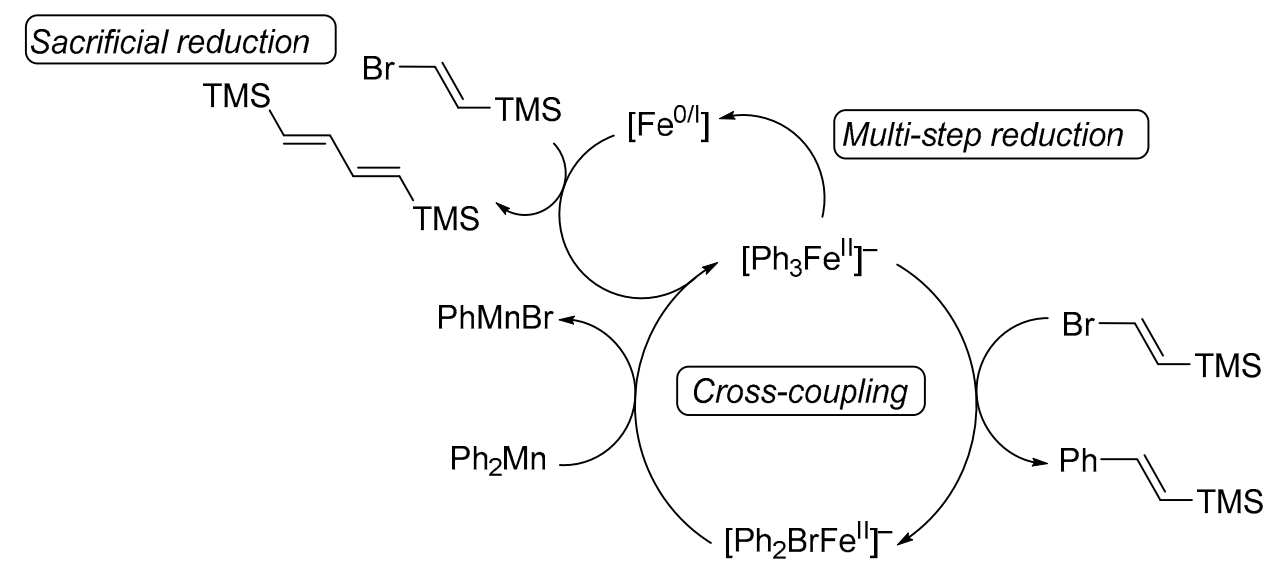

Scheme 3. Proposed catalytic cycle and side reactions for the aryl-alkenyl cross-coupling between $\mathrm{Ph}_{2} \mathrm{Mn}$ and an alkenyl bromide under Fe-catalytic conditions.

Kinetic studies will further be pursued in order to determine the global kinetics of the aryl-alkenyl cross-coupling reaction, and to examine the possibility for the low $\mathrm{Fe}^{0}$ and $\mathrm{Fe}^{\mathrm{I}}$ oxidation states involved in a cross-coupling catalytic cycle, in addition to the off-cycle sacrificial reduction of the alkenyl electrophile evidenced herein. Such studies will also help analyze the mechanism of the activation of the C-X bond of the alkenyl halide. Isomerization toward the sterically more stable $E$ coupling products may suggest the implication of an iron-based radical activation of the alkenyl halide, as observed in the case of alkyl electrophiles [44], albeit formation of the $\mathrm{C}_{\mathrm{sp} 2}$-centered radical is generally more energetically-demanding. Additionally, it cannot be excluded in an alternative scenario that isomerization of the $\mathrm{C}=\mathrm{C}$ bond occurs after the coupling step, akin to the observations made by Jacobi von Wangelin for the iron-catalyzed isomerization of Z-olefins to their $E$ analogues [45].

\section{Materials and Methods}

\subsection{Materials and Instruments}

All reactions, except otherwise noted, were carried out in flame-dried glassware equipped with magnetic stirring under an argon atmosphere using standard Schlenk techniques. To transfer solvents or reagents, syringes were used, which were purged three times with argon prior to use. After purification by flash column chromatography, products were concentrated using a rotary 
evaporator and, subsequently, dried under high vacuum. Indicated yields are isolated yields of compounds estimated to be $>95 \%$ pure, as determined by ${ }^{1} \mathrm{H}-\mathrm{NMR}\left(25^{\circ} \mathrm{C}\right)$ and capillary GC.

To examine the reaction progress of the performed reactions, GC-analysis of quenched hydrolyzed and iodolyzed reaction aliquots relative to an internal standard was used. For this purpose, small amounts of the reaction mixture were hydrolyzed using a saturated aqueous solution of $\mathrm{NH}_{4} \mathrm{Cl}$, subsequently extracted with EtOAc, dried over $\mathrm{MgSO}_{4}$ and gaschromatographically quantified. To monitor the process of directed metalations and oxidative insertion reactions, small amounts of the reaction mixture were iodolyzed. A small quantity of iodine was dissolved in freshly distilled THF $(0.50 \mathrm{~mL})$, charged with the reaction mixture, and added to a solution of $\mathrm{Na}_{2} \mathrm{~S}_{2} \mathrm{O}_{3}$. The mixture was extracted with EtOAc, dried over $\mathrm{MgSO}_{4}$, and was then gas chromatographically measured.

To determine the concentration of the different synthesized metallic reagents, iodometric titration was used. For this purpose, a known amount of iodine was charged with freshly distilled THF $(1.00 \mathrm{~mL})$ to give a deep red solution. The metallic reagent was added dropwise at $2{ }^{\circ} \mathrm{C}$ to the iodine solution until the red coloration went colorless. The concentration of the organometallic reagent could be calculated via the consumed volume of the reaction mixture and the amount of used iodine.

Thin layer chromatography (TLC) was implemented on alumina plates coated with $\mathrm{SiO}_{2}$ (Merck 60, F-254, Merck, Darmstadt, Germany). To visualize the spots of the different products, UV light was used.

Flash column chromatography was performed using $\mathrm{SiO}_{2}(0.04-0.06 \mathrm{~mm}, 230-400$ mesh) from Merck.

${ }^{1} \mathrm{H}-\mathrm{NMR},{ }^{13} \mathrm{C}-\mathrm{NMR},{ }^{19} \mathrm{~F}-\mathrm{NMR}$, and 2D-NMR spectra were recorded on VARIAN Mercury 200, BRUKER ARX 300, VARIAN VXR 400 S, and BRUKER AMX 600 instruments (Bruker, Billerica, MA, USA). Chemical shifts are reported as $\delta$-values in ppm relative to tetramethylsilane. The following abbreviations were used to characterize signal multiplicities: $s$ (singlet), d (doublet), $t$ (triplet), $\mathrm{q}$ (quartet), m (multiplet), and bs (broad singlet).

Mass spectroscopy: High resolution (HRMS) and low resolution (MS) spectra were recorded on a FINNIGAN MAT 95Q instrument (now Thermo Fisher company, Waltham, MA, USA). Electron impact ionization (EI) was conducted with an ionization energy of $70 \mathrm{eV}$. For coupled gas chromatography/mass spectrometry, a HEWLETT-PACKARD HP 6890 /MSD 5973 GC/MS system was used. Molecular fragments are reported starting at a relative intensity of $10 \%$.

Infrared spectra (IR) were recorded from $4500 \mathrm{~cm}^{-1}$ to $650 \mathrm{~cm}^{-1}$ on a PERKIN ELMER Spectrum BX59343 instrument (Perkin Elmer, Wellesley, MA, USA). For detection, a SMITHS DETECTION DuraSampIIR IIDiamond ATR sensor (Smiths Detection, Hemel Hempstead, UK) was used. Wavenumbers are reported in $\mathrm{cm}^{-1}$ starting at an absorption of $10 \%$.

Melting points (m.p.) were determined on a BÜCHI B-540 melting point apparatus (BÜCHI LabortechnikAG, Flawil, Switzerland) and are uncorrected. Compounds decomposing upon melting are indicated by (decomp.).

Gas chromatography was executed with machines of type Agilent Technologies 7890A GC-Systems with 6890 GC inlets, detectors (Agilent, Santa Clara, CA, USA), a GC oven, and a column of type HP 5 (Hewlett-Packard, $5 \%$ phenylmethylpolysiloxane; length: $10 \mathrm{~m}$, diameter: $0.25 \mathrm{~mm}$, film thickness: $0.2 \mu \mathrm{m})$.

Gas chromatography-Mass spectra were recorded on a networking system called Hewlett-Packard 6890/MSD 5973 GC/MS (Hewlett Packard, Palo Alto, CA, USA) with a column of type HP 5 (Hewlett-Packard, $5 \%$ phenylmethylpolysiloxane; length: $10 \mathrm{~m}$, diameter: $0.25 \mathrm{~mm}$, film thickness: $0.2 \mu \mathrm{m})$.

\subsection{Chemicals, Solvents, and Typical Procedures}

All chemicals were purchased from commercial sources and were used without any further purification unless otherwise noted. 
THF was continuously refluxed and freshly distilled from benzophenone ketyl under nitrogen. The freshly distilled THF was stored over a molecular sieve (4 Å) under argon. Solvents for column chromatography were distilled prior to use.

\subsubsection{Typical Procedure for the One-Pot Preparation of Bis-(aryl)manganese Reagents 1a-g}

A dry and argon-flushed Schlenk-tube, equipped with a magnetic stirring bar and a rubber septum, was charged with $\mathrm{LiCl}\left(0.610 \mathrm{~g}, 14.4 \mathrm{mmol}, 2.4\right.$ equiv.), heated to $450{ }^{\circ} \mathrm{C}$ under high vacuum, and then cooled to room temperature. After being switched to argon, the same procedure was applied after $\mathrm{MnCl}_{2}$ was added ( $453 \mathrm{mg}, 3.60 \mathrm{mmol}, 0.6$ equiv.). After cooling to room temperature, magnesium turnings were added $(0.350 \mathrm{~g}, 14.4 \mathrm{mmol}, 2.4$ equiv.), which was followed by freshly distilled THF $(12 \mathrm{~mL})$. After the reaction mixture was cooled to $-5{ }^{\circ} \mathrm{C}$, the aryl bromides $\mathbf{2 a}-\mathbf{g}$ were then added dropwise using $1 \mathrm{~mL}$ syringes $(6.0 \mathrm{mmol}, 1.0$ equiv., addition time: $1 \mathrm{~min})$ and the reaction mixture was stirred until a complete conversion of the starting material was observed. The reaction progress was monitored by GC-analysis of hydrolyzed and iodolyzed aliquots.

When the metalation was completed, the concentration of the bis-(aryl)manganese species was determined by titration against iodine in freshly distilled THF. The black solutions of the aryl reagents 1a-g were then separated from the magnesium turnings using a syringe and, subsequently, transferred into another pre-dried and argon-flushed Schlenk-tube, which was cooled to $-5^{\circ} \mathrm{C}$. After a titration against iodine in freshly distilled THF was performed, the reagent was ready to use for Cross-Couplings.

4.2.2. Typical Procedure for the Cross-Coupling Reactions of Bis-(aryl)manganese Reagents 1a-g with Different Electrophiles 3a-e

A pre-dried and argon-flushed Schlenk-tube equipped with a magnetic stirring bar and a rubber septum was charged with $\mathrm{Fe}(\mathrm{acac})_{3}(35 \mathrm{mg}, 0.10 \mathrm{mmol}, 10 \mathrm{~mol} \%)$, the corresponding electrophile (3a-e, $1.0 \mathrm{mmol}, 1.0$ equiv.), tetradecane as internal standard $(50 \mu \mathrm{L})$ and freshly distilled THF $(1.0 \mathrm{~mL})$ as solvent. The reaction mixture was cooled to $0{ }^{\circ} \mathrm{C}$ and the bis-(aryl)manganese solution (1a-g, 0.6 equiv.) was added dropwise whereupon a color change to dark brown could be recognized. After the addition was complete, the reaction mixture was stirred for a given time at room temperature and the completion of the cross-coupling reaction was monitored by GC-analysis of hydrolyzed aliquots. Thereupon, a saturated aqueous solution of $\mathrm{NH}_{4} \mathrm{Cl}$ was added and the aqueous layer was extracted with EtOAc $(3 \times 100 \mathrm{~mL})$. The combined organic layers were dried over $\mathrm{MgSO}_{4}$, filtered, and concentrated under reduced pressure. Purification of the crude products by flash column chromatography afforded the desired cross-coupling reaction products $(4 \mathrm{a}-\mathrm{k}, \mathbf{4 m}, \mathbf{4 n})$.

\subsection{Studies on the Catalytically Active Species and Catalytic Cycle}

All the samples were prepared in a recirculating JACOMEX inert atmosphere (Ar) drybox and vacuum Schlenk lines. Glassware was dried overnight at $120^{\circ} \mathrm{C}$ before use. NMR spectra were obtained using a Bruker DPX $400 \mathrm{MHz}$ spectrometer (Bruker, Billerica, MA, USA). Chemical shifts for ${ }^{1} \mathrm{H}$-NMR spectra were referenced to solvent impurities (herein, THF). NMR tubes were equipped with a J. Young valves were used for all ${ }^{1} \mathrm{H}-\mathrm{NMR}$ experiments and catalytic tests. The GC-MS analysis was performed using $n$-decane as an internal standard. The reaction media aliquots were quenched by the addition of distilled water under air. The organic products were extracted using DCM, and injected into the GC-MS. Mass spectra were recorded on a Hewlett-Packart HP 5973 mass spectrometer (Hewlett Packard, Palo Alto, CA, USA) via a GC-MS coupling with a Hewlett-Packart HP 6890 chromatograph (Hewlett Packard, Palo Alto, CA, USA) equipped with a capillary column HP-5MS (50 m $\times 0.25 \mathrm{~mm} \times$ $0.25 \mu \mathrm{m}$, Hewlett Packard, Palo Alto, CA, USA). Ionisation was due to an electronic impact (EI, $70 \mathrm{eV}$ ).

\section{Conclusions}

In summary, various functionalized bis-(aryl)manganese species have been readily prepared in one-pot conditions from the corresponding aryl bromides by inserting magnesium in the presence of 
$\mathrm{LiCl}$ and in situ trans-metalation with $\mathrm{MnCl}_{2}$ in $\mathrm{THF}$ at $-5^{\circ} \mathrm{C}$ within $2 \mathrm{~h}$. These bis-(aryl)manganese reagents have been allowed to undergo smooth iron-catalyzed cross-couplings using $10 \mathrm{~mol} \% \mathrm{Fe}(\mathrm{acac})_{3}$ and various functionalized alkenyl iodides and bromides at $25^{\circ} \mathrm{C}$ for $1 \mathrm{~h}$. Mechanistic investigations carried out by ${ }^{1} \mathrm{H}-\mathrm{NMR}$ showed that ate-iron(II) species $\left[\mathrm{Ar}_{3} \mathrm{Fe}^{\mathrm{II}}\right]^{-}$are formed by trans-metalation of the bis-(aryl)manganese reagent with the iron catalyst, and that they can react with alkenyl bromides to afford the expected cross-coupling product. Low-valent $\mathrm{Fe}^{0}$ and $\mathrm{Fe}^{\mathrm{I}}$ oxidation states can also be formed by the reduction of the ate-iron(II) catalyst under these conditions. This leads to the sacrificial reduction of the alkenyl electrophile via an off-cycle pathway, which partly regenerates the $\mathrm{Fe}^{\mathrm{II}}$ oxidation state, where the latter is able to enter a new catalytic cycle.

Supplementary Materials: The following are available online. Additional synthesis and characterization (NMR, IR, HRMS, m.p.) data are available online.

Author Contributions: Conceptualization, G.L. and P.K. Methodology, A.D. and L.R. Writing-original draft preparation, G.L., L.R., and A.D. Writing—review and editing, G.L. and P.K. Supervision, G.L. and P.K. Project administration, G.L. and P.K. Funding acquisition, G.L. and P.K. All authors have read and agreed to the published version of the manuscript.

Funding: This work was supported by the CNRS, Chimie ParisTech (Paris), and LMU (Munich) in the framework of the International Associated Laboratory IrMaCar.

Acknowledgments: We thank the DFG (SFB749) for financial support, and Albemarle (Germany) and BASF (Ludwigshafen, Germany) for the generous gift of chemicals. G.L. also thanks the ANR research program (project JCJC SIROCCO). Aurélien Adenot (CEA Saclay) is warmly thanked for his kind technical assistance.

Conflicts of Interest: The authors declare no conflict of interest.

\section{References and Notes}

1. Crawley, M.L.; Trost, B.M. Applications of Transition Metal Catalysis in Drug Discovery and Development: An Industrial Perspective; John Wiley \& Sons: Hoboken, NJ, USA, 2012.

2. Miyaura, N. Cross-Coupling Reactions. A Practical Guide. Org. Process Res. Dev. 2003, 7, 1084. [CrossRef]

3. Phapale, V.B.; Cárdenas, D.J. Nickel-Catalysed Negishi cross-coupling reactions: Scope and mechanisms. Chem. Soc. Rev. 2009, 38, 1598-1607. [CrossRef] [PubMed]

4. Hartwig, J.F. Organotransition Metal Chemistry. From Bonding to Catalysis. Angew. Chem. Int. Ed. 2010, 49, 7622. [CrossRef]

5. Jana, R.; Pathak, T.P.; Sigman, M.S. Advances in Transition Metal ( $\mathrm{Pd}, \mathrm{Ni}, \mathrm{Fe})$-Catalyzed Cross-Coupling Reactions Using Alkyl-organometallics as Reaction Partners. Chem. Rev. 2011, 111, 1417-1492. [CrossRef] [PubMed]

6. $\quad \mathrm{LD}_{50}\left(\mathrm{FeCl}_{2}\right.$, rat oral $)=900 \mathrm{mg} / \mathrm{kg} ; \mathrm{LD}_{50}\left(\mathrm{NiCl}_{2}\right.$, rat oral $)=186 \mathrm{mg} / \mathrm{kg}$.

7. Egorova, K.S.; Ananikov, V.P. Which Metals are Green for Catalysis? Comparison of the Toxicities of $\mathrm{Ni}, \mathrm{Cu}$, $\mathrm{Fe}, \mathrm{Pd}, \mathrm{Pt}, \mathrm{Rh}$, and Au Salts. Angew. Chem. Int. Ed. 2016, 55, 12150-12162. [CrossRef] [PubMed]

8. $\mathrm{FeCl}_{2}$ ca. $332 € / \mathrm{mol}, \mathrm{PdCl}_{2}$ ca. $6164 € / \mathrm{mol}$; prices retrieved from Alfa Aesar in August 2019.

9. Thapa, S.; Shrestha, B.; Gurung, S.K.; Giri, R. Copper-catalysed cross-coupling: An untapped potential. Org. Biomol. Chem. 2015, 13, 4816-4827. [CrossRef]

10. Fürstner, A.; Leitner, A.; Méndez, M.; Krause, H. Iron-Catalyzed Cross-Coupling Reactions. J. Am. Chem. Soc. 2002, 124, 13856-13863. [CrossRef]

11. Bedford, R.B.; Brenner, P.B. Iron Catalysis II; Bauer, E., Ed.; Springer: Berlin, Germany, 2015.

12. Cahiez, G.; Moyeux, A.; Cossy, J. Grignard Reagents and Non-Precious Metals: Cheap and Eco-Friendly Reagents for Developing Industrial Cross-Couplings. A Personal Account. Adv. Synth. Catal. 2015, 357, 1983-1989. [CrossRef]

13. Bauer, I.; Knölker, H.-J. Iron Catalysis in Organic Synthesis. Chem. Rev. 2015, 115, 3170-3387. [CrossRef]

14. Cahiez, G.; Moyeux, A. Cobalt-Catalyzed Cross-Coupling Reactions. Chem. Rev. 2010, 110, 1435-1462. [CrossRef]

15. Cahiez, G.; Duplais, C.; Buendia, J. Chemistry of Organomanganese(II) Compounds. Chem. Rev. 2009, 109, 1434-1476. [CrossRef] [PubMed] 
16. Peng, Z.; Li, N.; Sun, X.; Wang, F.; Xu, L.; Jiang, C.; Song, L.; Yan, Z.-F. The transition-metal-catalyst-free oxidative homocoupling of organomanganese reagents prepared by the insertion of magnesium into organic halides in the presence of $\mathrm{MnCl}_{2} \cdot 2 \mathrm{LiCl}$. Org. Biomol. Chem. 2014, 12, 7800-7809. [CrossRef] [PubMed]

17. Haas, D.; Hammann, J.M.; Moyeux, A.; Cahiez, G.; Knochel, P. Oxidative Homocoupling of Diheteroaryl- or Diarylmanganese Reagents Generated via Directed Manganation Using TMP 2 Mn. Synlett 2015, 26, 1515. [CrossRef]

18. Cahiez, G.; Masuda, A.; Bernard, D.; Normant, J.F. Reactivite des derives organo-manganeux.I-action sur les chlorures d'acides. synthese de cetones. Tetrahedron Lett. 1976, 36, 3155-3156. [CrossRef]

19. Friour, G.; Alexakis, A.; Cahiez, G.; Normant, J.F. Reactivite des derives organomanganeux-VIII: Préparation de cétones par acylation d'organomanganeux. Influence de la nature de l'agent acylant, des solvants et des ligands. Tetrahedron 1984, 40, 683-693. [CrossRef]

20. Kauffmann, T.; Bisling, M. Zwei neue reaktionsweisen von alkyl-Mn(II)-verbindungen: 1,4-addition an cyclohex-2-enon(1) und desoxygenierung von oxiranen (1). Tetrahedron Lett. 1984, 25, 293-296. [CrossRef]

21. Cahiez, G.; Alami, M. Organomanganese (II) reagents XI.: A study of their reactions with cyclic conjugated enones: Conjugate addition and reductive dimerization. Tetrahedron Lett. 1986, 27, 569-572. [CrossRef]

22. Cahiez, G.; Alami, M. Organomanganese (II) reagents XVI1: Copper-catalyzed 1,4-addition of organomanganese chlorides to conjugated enones. Tetrahedron Lett. 1989, 30, 3541-3544. [CrossRef]

23. Cahiez, G.; Alami, M. Composés organomanganeux XXI. Réaction d'un composé organomanganeux avec une énone conjuguée: Influence d'un acide de Lewis, d'un sel de fer ou d'un sel de nickel. J. Organomet. Chem. 1990, 397, 291-298. [CrossRef]

24. Quinio, P.; Benischke, A.D.; Moyeux, A.; Cahiez, G.; Knochel, P. New Preparation of Benzylic Manganese Chlorides by the Direct Insertion of Magnesium into Benzylic Chlorides in the Presence of $\mathrm{MnCl}_{2} \cdot 2 \mathrm{LiCl}$. Synlett 2015, 26, 514. [CrossRef]

25. Cahiez, G.; Marquais, S. Highly Chemo- and Stereoselective Fe-Catalyzed Alkenylation of Organomanganese Reagents. Tetrahedron Lett. 1996, 37, 1773-1776. [CrossRef]

26. Desaintjean, A.; Belrhomari, S.; Rousseau, L.; Lefèvre, G.; Knochel, P. Iron-Catalyzed Cross-Coupling of Functionalized Benzylmanganese Halides with Alkenyl Iodides, Bromides, and Triflates. Org. Lett. 2019, 21, 8684-8688. [CrossRef] [PubMed]

27. Tamao, K.; Sumitani, K.; Kumada, M. Selective carbon-carbon bond formation by cross-coupling of Grignard reagents with organic halides. Catalysis by nickel-phosphine complexes. J. Am. Chem. Soc. 1972, 94, 4374-4376. [CrossRef]

28. Haas, D.; Hammann, J.F.; Greiner, R.; Knochel, P. Recent Developments in Negishi Cross-Coupling Reactions. ACS Catal. 2016, 6, 1540-1552. [CrossRef]

29. O’Donovan, M.R.; Mee, C.D.; Fenner, S.; Teasdale, A.; Phillips, D.H. Boronic acids-a novel class of bacterial mutagen. Mutat. Res. 2011, 724, 1-6. [CrossRef]

30. Hansen, M.M.; Jolly, R.A.; Linder, R.J. Boronic Acids and Derivatives-Probing the Structure-Activity Relationships for Mutagenicity. Org. Process Res. Dev. 2015, 19, 1507-1516. [CrossRef]

31. Benischke, A.D.; Desaintjean, A.; Juli, T.; Cahiez, G.; Knochel, P. Nickel-Catalyzed Cross-Coupling of Functionalized Organo-manganese Reagents with Aryl and Heteroaryl Halides Promoted by 4-Fluorostyrene. Synthesis 2017, 49, 5396. [CrossRef]

32. Cahiez, G.; Gager, O.; Lecomte, F. Manganese-Catalyzed Cross-Coupling Reaction between Aryl Grignard Reagents and Alkenyl Halides. Org. Lett. 2008, 10, 5255-5256. [CrossRef]

33. Additionally, ${ }^{55} \mathrm{Mn}$ nucleus is quadrupolar (100\% natural abundance, $\left.\mathrm{I}=5 / 2\right)$.

34. Morris, R.J.; Girolami, G.S. High-valent organomanganese chemistry. 2. Synthesis and characterization of manganese(III) aryls. Organometallics 1991, 10, 799-804. [CrossRef]

35. Krasovskiy, A.; Knochel, P. Convenient Titration Method for Organometallic Zinc, Magnesium, and Lanthanide Reagents. Synthesis 2006, 5, 890. [CrossRef]

36. Fischer, R.; Görls, H.; Friedrich, M.; Westerhausen, M. Reinvestigation of arylmanganese chemistry-Synthesis and molecular structures of $\left[(\text { thf })_{4} \mathrm{Mg}(\mu-\mathrm{Cl})_{2} \mathrm{Mn}(\mathrm{Br}) \mathrm{Mes}\right]$, [Mes(thf) $\left.\mathrm{Mn}(\mu-\mathrm{Mes})\right]_{2}$, and $\left(\mathrm{MnPh}_{2}\right)^{\infty}\left(\mathrm{Ph}=\mathrm{C}_{6} \mathrm{H}_{5}\right.$; Mes= mesityl, 2,4,6-Me $\left.{ }_{3} \mathrm{C}_{6} \mathrm{H}_{2}\right)$. J. Organomet. Chem. 2009, 694, 1107-1111. [CrossRef]

37. Meyer, R.M.; Hanusa, T.P. Structural organomanganese chemistry. In The Chemistry of Organomanganese Compounds; Rappoport, Z., Marek, I., Eds.; Wiley: Hoboken, NJ, USA, 2011; p. 45. 
38. Bedford, R.B.; Brenner, P.B.; Carter, E.; Cogswell, P.M.; Haddow, M.F.; Harvey, J.N.; Murphy, D.M.; Nunn, J.; Woodall, C.H. TMEDA in Iron-Catalyzed Kumada Coupling: Amine Adduct versus Homoleptic "ate" Complex Formation. Angew. Chem. Int. Ed. 2014, 53, 1804-1808. [CrossRef] [PubMed]

39. Muñoz, S.B.; Daifuku, S.L.; Sears, J.D.; Baker, T.M.; Carpenter, S.H.; Brennessel, W.W.; Neidig, M.L. The N-Methylpyrrolidone (NMP) Effect in Iron-Catalyzed Cross-Coupling with Simple Ferric Salts and MeMgBr. Angew. Chem. Int. Ed. 2018, 57, 6496-6500. [CrossRef] [PubMed]

40. Clémancey, M.; Cantat, T.; Blondin, G.; Latour, J.-M.; Dorlet, P.; Lefèvre, G. Structural insights into the nature of $\mathrm{Fe}^{0}$ and $\mathrm{Fe}^{\mathrm{I}}$ low-valent species obtained upon reduction of Iron salts by Aryl Grignard reagents. Inorg. Chem. 2017, 56, 3834-3848. [CrossRef]

41. Rousseau, L.; Herrero, C.; Clémancey, M.; Imberdis, A.; Blondin, G.; Lefèvre, G. Evolution of ate organoiron(II) species towards lower oxidation states: Role of the steric and electronic factors. Chem. Eur. J. 2019. [CrossRef]

42. The mechanistic studies were pursued using only aryl Grignard nucleophiles, as the transmetalation of the latter with iron was proceeding in the same way than that of manganese, and as the NMR spectra allowed a much more precise and accurate interpretation thanks to the absence of highly paramagnetic Mn-containing species.

43. Cheng, J.; Chen, Q.; Leng, X.; Ye, S.; Deng, L. Three-Coordinate Iron(0) complexes with N-Heterocyclic Carbene and Vinyltrimethylsilane Ligation: Synthesis, Characterization, and Ligand Substitution Reactions. Inorg. Chem. 2019, 58, 13129-13141. [CrossRef]

44. Mo, Z.; Deng, L. Open-shell iron hydrocarbyls. Coord. Chem. Rev. 2017, 350, 285-299. [CrossRef]

45. Mayer, M.; Welther, A.; Jacobi von Wangelin, A. Iron-Catalyzed Isomerizations of Olefins. ChemCatChem 2011, 3, 1567-1571. [CrossRef]

Sample Availability: Samples of all the compounds described in this article are available from the authors.

(C) 2020 by the authors. Licensee MDPI, Basel, Switzerland. This article is an open access article distributed under the terms and conditions of the Creative Commons Attribution (CC BY) license (http://creativecommons.org/licenses/by/4.0/). 